\title{
Importance of spiritual well-being in assessment of recovery: the Service-user Recovery Evaluation (SeRvE) scale
}

\author{
Joanna M. Barber, ${ }^{1}$ Madeleine Parkes, ${ }^{1}$ Helen Parsons, ${ }^{2}$ Christopher C. H. Cook $^{3}$
}

The Psychiatrist (2012), 36, 444-450, doi: 10.1192/pb.bp.111.037838

${ }^{1}$ Birmingham and Solihull Mental Health NHS Foundation Trust, Birmingham; ${ }^{2}$ Warwick Medical School, The University of Warwick, Warwick; ${ }^{3}$ Durham University, Durham

Correspondence to Joanna Barber (Joanna.Barber@bsmhft.nhs.uk)

First received 18 Nov 2011, final revision 10 Apr 2012, accepted 31 May 2012

\begin{abstract}
Aims and method To develop a self-report questionnaire to measure mental health recovery from the service user viewpoint. Literature searches and scoping exercises indicated that psychological, social and spiritual issues should be included. The resultant provisional scale was completed by 107 service users.

Results The provisional scale was shortened as a result of factor analysis. The finalised version was highly reliable (Cronbach's alpha 0.911) and valid, correlating significantly with an already established recovery scale. It contained nine recognisable subscales, the first two describing existential and religious well-being. Separate well-being and ill-being factors were also identified.

Clinical implications An inclusive tool for service users' assessment of their own recovery, the Service User Recovery Evaluation (SeRvE) scale, has been validated. This can be used both as a research tool and clinically to monitor interventions. The importance of spiritual care for service users is highlighted.
\end{abstract}

Declaration of interest None.
There is evidence that clinicians and their patients often have a different view of recovery from mental illness. ${ }^{1}$ Traditionally, clinicians tend to focus on specific symptom reduction, ${ }^{2}$ whereas patients focus more generally on the psychological, the social and the spiritual. ${ }^{1}$ Even clinicians' rating of symptoms can be very different from that of the service user. ${ }^{3}$ There are well-established methods by which clinicians can make assessments of the recovery of their patients. Symptom severity is often recorded using the Health of the Nation Outcome Scales (HoNOS) tool. ${ }^{4}$ However there is a shortage of scales for service users to rate their own recovery. For service users, recovery can occur even alongside psychosis and does not necessarily mean cure; ${ }^{5}$ some even see their symptoms as a meaningful creative opportunity. ${ }^{6,7}$ The present study compiles a scale for service users to assess their own view of their recovery. It is concerned with psychological, social and spiritual aspects of recovery without making any attempt to directly measure symptom severity.

The psychological and social dimensions of recovery have been frequently written about ${ }^{8-15}$ and there are already some scales in the literature to measure them, although none inclusive of all the issues raised. ${ }^{16-23}$ To date the spiritual component of recovery has been rather neglected, despite its proven importance to many service users. ${ }^{24}$ Spirituality is that which gives meaning, purpose and hope, whether or not it includes a formal religious faith. ${ }^{25}$ In his paper of 2004, Cook (p. 548) ${ }^{26}$ attempts a working definition:
Spirituality is a distinctive, potentially creative and universal dimension of human experience arising from both within the inner subjective awareness of individuals and within commu- nities, social groups and traditions. It may be experienced as relationship with that which is intimately inner, immanent and personal, within the self or others and/or as relationship with that which is wholly other, transcendent and beyond the self. It is experienced as being of fundamental or ultimate importance and is thus concerned with matters of meaning and purpose in life, truth and values.

Spiritual well-being occurs when this experience of spirituality adds to overall well-being. It is seen as crucial by many service users for their recovery, ${ }^{27}$ thus it is important that this dimension is included in our new scale.

Despite the existence of many measures of spiritual well-being. ${ }^{28}$ there is not one specifically for mental health service users. The Spiritual Well-Being Scale (SWBS) of Ellison has been used for this purpose in some studies. ${ }^{29,30}$ It has two subscales, religious and existential. In a previous pilot study we found the SWBS to be unsuitable here in Birmingham, UK, due to the religious subscale being expressed in evangelical, Christian language. Understandably, this was largely meaningless in the context of a multicultural, multifaith population. As purely religious issues are important for many service users, ${ }^{31,32}$ it is necessary to include a measure of religious well-being in our scale but the questions need to be more appropriate. 
The existential subscale of the SWBS is more easily understood by our service users, being concerned with experience and meaning of life in general. This subscale overlaps in subject matter with scales of psychological wellbeing. ${ }^{14}$ It was decided that it is impossible to separate manifestations of existential well-being and psychological well-being, and that it was suitable to combine the psychosocial and existential dimensions, with a measure of religious well-being, into one inclusive scale of recovery from the service user's viewpoint. It has been named the Service-user Recovery Evaluation (SeRvE) scale.

\section{Method}

\section{The team}

The team had multidisciplinary input, led by a long-term service user (J.M.B.), supported by a research assistant (M.P.) and a consultant psychiatrist who is also a theologian (C.C.H.C.). A medical statistician (H.P.) was recruited to the team during the project to provide specialist support.

\section{Design of the SeRvE scale}

Concerning psychosocial issues, a literature search revealed a wide range of topics valued by service users for recovery. ${ }^{8,9,11,33-35}$ This included hope, self-esteem, empowerment, good relationships, positive and stable affect, stigma and shame, identity, meaning, purpose and satisfaction with life. From this a comprehensive list of questions about psychosocial recovery was compiled. This list had been tested with 37 service users in an unpublished pilot study by the same research team and found to be reliable and valid.

Concerning spiritual issues, a new list of spiritual wellbeing questions was drawn up, based on broader definitions of spirituality ${ }^{25,26,36-42}$ and existing scales. ${ }^{43-46}$ This included existential as well as purely religious issues. The existential questions overlapped with the psychosocial as described above. The questions on religious matters were designed to be accessible, encouraging participants to insert their own word for God or higher power according to their particular religion or belief systems. Questions were added concerning specific religious problems that some service users report. ${ }^{47}$ A scoping day at the University of Birmingham was then held, in which 30 mental health service users gave their views on spirituality and its importance for their mental health. Many people had a religious faith of some sort that was important and helpful to them. For some the concept of connectedness was important for their spiritual well-being. Many people derived spiritual inspiration from the arts, music or nature. Some new questions were added accordingly. Each question from the list was then rated by the participants from one to three for both ease of understanding and relevance to spiritual well-being. Questions were discarded if their mean score for either was less than two.

This list of existential and religious questions was then combined with the list of psychosocial questions to make a provisional inclusive scale of service user recovery. Feedback was received from the service users' in research forum at the University of Birmingham, Suresearch. The resultant scale (provisional SeRvE), contained 67 questions answered on a five-point Likert scale, numbered from one to five, and was set out in subject headings for ease of completion (how you feel about your life, your emotions, your relationships and your religious well-being). Each part contained a mixture of positively and negatively worded questions. For the faith-based questions, the option of answering 'not applicable' (n/a) was given, for people to whom these particular questions meant nothing.

\section{Other scales used}

Two other scales were used in this study. The first was the Mental Health Recovery Measure (MHRM), ${ }^{22}$ an established scale of service user recovery. The second was the Spiritual Well-Being Questionnaire (SWBQ), ${ }^{48}$ an established scale of spiritual well-being. These scales were chosen to be appropriate to look for correlations with the SeRvE scale for purposes of validation.

\section{Sample}

A convenience sample of 107 working age, adult mental health service users was recruited, half from in-patient and half from out-patient units from four wards, four day centres and one out-patient clinic, all in Birmingham and Solihull Mental Health NHS Foundation Trust. Units were visited in turn and clinical staff suggested patients who might be agreeable to participate. At each visit, all available patients were invited. However, we acknowledge that our sample is likely to be biased in favour of the patients who were less acutely unwell, these being more able and willing to participate. Exclusion criteria were individuals under 18, people with known organic brain disease and those with concurrent acute physical illness. People over 65 were also excluded because of the increased possibility of them having early stage organic brain dysfunction.

\section{Study design}

This study was approved by the Black Country Research Ethics Committee, on 3 August 2010, REC reference number 10/H1202/52. Potential participants were approached by a member of the clinical staff. If they were agreeable, the research assistant gave them the information sheet to read. If they gave fully informed consent, they were given the three questionnaires (provisional SeRvE scale, MHRM and SWBQ) to complete. Assistance in reading the questions, from a staff member or one of the research team, was available if requested. The completed questionnaires with signed consent forms were then returned to the research assistant. Also recorded were: date of birth, gender, unit they were in, the nature of their religious faith, if applicable, and the importance to them of their spirituality. Participants were asked whether they would consent to their medical notes being accessed by the research team to retrieve diagnosis; only $50 \%$ gave such consent.

\section{Data analysis}

Results from all the questionnaires were entered manually onto a computer and analysed with SPSS software (version 
Table 1 Importance of religious faith and spirituality to service users

\begin{tabular}{|c|c|c|c|c|c|c|}
\hline & \multicolumn{5}{|c|}{ Importance of spirituality } & \multirow[b]{2}{*}{ Total } \\
\hline & Not at all & A little & Quite a lot & Very much so & Don't know & \\
\hline \multicolumn{7}{|c|}{ Belief in a higher power } \\
\hline Not at all & 7 & 2 & 1 & 1 & 1 & 12 \\
\hline A little & 3 & 6 & 2 & 0 & 0 & 11 \\
\hline Quite a bit & 0 & 5 & 4 & 5 & 3 & 17 \\
\hline Very much so & 1 & 12 & 10 & 24 & 5 & 52 \\
\hline Don't know & 3 & 1 & 2 & 1 & 0 & 7 \\
\hline Total & 14 & 26 & 19 & 31 & 9 & 99 \\
\hline
\end{tabular}

18 for Windows). All negative questions were scored negatively, for example a high score for agitation (5) would be entered as the appropriate low score (1). Factor analysis was performed to look for meaningful categories within the provisional SeRvE scale. For this, any not applicable responses from faith-based questions were encoded as zeros to distinguish them from random missing values. First, the data were checked for correlations via Bartlett's test of sphericity, which found that the variables were correlated with each other $(P<0.01)$. The KaiserMeyer-Olkin measure of sampling adequacy was calculated at 0.739. The data are therefore suitable for principal component analysis (PCA). A PCA using varimax orthogonal rotation was used to maximise the differences between factors. Item communalities were all found to be greater than 0.5 , hence all item variances are well represented in the model. Factors were only retained if they had an eigenvalue of greater than one. Items were each checked to see whether they loaded onto a single factor with a correlation of 0.45 or greater. Any items that loaded onto multiple factors, or did not load onto any retained factors, were removed. Hence, a revised, shorter version of the provisional scale was constructed and assumptions re-checked. The variables were still correlated (Bartlett's test of sphericity $P<0.001$ ), and the Kaiser-Meyer-Olkin measure of sampling adequacy increased to 0.763. The smallest item communality found was 0.549.

To compensate for faith-based questions that were scored 'not applicable' by respondents, the final total SeRvE score for each respondent was calculated as a percentage of the total number of questions answered. This ensures that the total score of each respondent is directly comparable, and is the method of choice for use of the scale both clinically and in research. Pearson's correlations of the SeRvE scale with the MHRM and SWBQ were then calculated, including all participants with a fully completed MHRM $(n=100)$ and SWBQ $(n=98)$. The reliability index, Cronbach's alpha, was calculated for the total finalised SeRvE scale and the nine subscales.

\section{Results}

\section{Our sample}

A wide variety of diagnoses was represented in the sample, however it was only possible to trace exact diagnoses for 42 individuals. Of these, 15 had bipolar disorder, 11 schizophrenia, 12 depression, 2 had an unspecified mental illness and 2 personality disorder. There were 51 in-patients, 24 day patients and 32 out-patients. There was a wide spread of religious or belief affiliation as described by the participants, including Christian, Muslim, Hindu, Sikh, Jewish, Buddhist, Wiccan, Atheist and Humanist. Table 1 shows that a religious belief of some sort is important to the majority of service users, and that most have a significant sense of spirituality. There is also a significant association between the two variables (Pearson's $\chi^{2}=48.36, P<0.01$ ), with respondents giving a similar response to both importance of spirituality and belief in a higher power. However, there are a few respondents who place a high importance on spirituality but who have little belief in a higher power.

\section{Reliability of total finalised SeRvE scale}

Cronbach's alpha for the total finalised scale was found to be 0.911, indicating high internal reliability and consistency. For each item, 'Cronbach's alpha if item deleted' was computed. No items had an undue influence on the rest of the scale.

\section{Correlations}

Despite the difference in subject matter between the three scales, the finalised SeRvE, MHRM and SWBQ correlated highly with each other (Table 2). The correlation between the SeRvE scale and MHRM confirms the validity of the SeRvE as a scale of recovery from mental illness. The high correlation of the SeRvE with the SWBQ indicates that including spiritual well-being in a scale of recovery from mental illness is important. However, the SeRvE scale itself remains unique in including psychosocial and spiritual issues in one scale specifically for mental health service users.

\begin{tabular}{|lccc|}
\hline Table 2 & $\begin{array}{l}\text { Correlations between Service-user Recovery } \\
\text { Evaluation (SeRvE), Spiritual Well-Being } \\
\text { Questionnaire (SWBQ) and Mental Health } \\
\text { Recovery Measure (MHRM) }\end{array}$ \\
\hline SeRvE & 1 & $0.882^{* *}$ & $0.731^{\star *}$ \\
\hline MHRM & $0.882^{* *}$ & 1 & $0.739^{* *}$ \\
\hline SWBQ & $0.731^{* *}$ & $0.739^{* *}$ & 1 \\
\hline
\end{tabular}

${ }^{\star *}$ Pearson's correlation coefficient significant at the 0.001 level, two-tailed. 


\begin{tabular}{|c|c|c|c|c|c|}
\hline Factor & Eigenvalue & $\%$ variance & Cumulative variance & Cronbach's $\alpha$ & Mean raw data (1-5) \\
\hline 1. Existential well-being & 10.708 & 26.771 & 26.771 & 0.900 & 3.734 \\
\hline 2. Religious well-being & 5.007 & 12.518 & 39.289 & 0.882 & 3.084 \\
\hline 3. Emotional state & 3.231 & 8.078 & 47.366 & 0.861 & 2.879 \\
\hline 4. Social well-being & 2.161 & 5.403 & 52.770 & 0.859 & 3.944 \\
\hline 5. Social ill-being & 1.530 & 3.826 & 56.596 & 0.757 & 3.320 \\
\hline 6. Connectedness & 1.416 & 3.540 & 60.135 & 0.733 & 2.969 \\
\hline 7. Religious ill-being & 1.216 & 3.039 & 63.174 & 0.745 & 3.446 \\
\hline 8. Existential ill-being & 1.112 & 2.780 & 65.954 & 0.702 & 3.431 \\
\hline 9. Stigma and shame & 1.031 & 2.578 & 68.533 & 0.676 & 2.972 \\
\hline
\end{tabular}

a. For a more detailed version that includes the questions summarised by each factor see online Table DS1.

\section{Factor analysis of the finalised SeRvE scale}

Table 3 shows the factor analysis of the finalised scale, forming nine meaningful subscales (see online Table DS1 for a more detailed version with the questions that loaded onto each factor summarised and see the Appendix for the questionnaire). There were no other factors with eigenvalues of more than one. The largest factor, Factor 1, consisted of nine questions regarding the respondents' existential well-being, and the second largest factor, Factor 2, comprises of seven questions about religious well-being. The reverse-coded questions exploring religious and existential ill-being loaded separately on Factors 7 and 8 respectively. Factor 3 shows the respondent's emotional state and Factor 9 illustrates stigma and shame. Factors 4 and 5 show the social well-being and social ill-being, and Factor 6 measures lack of connectedness, the importance of which had emerged in our scoping day. Cronbach's alpha for each subscale suggests that each one is reliable in its own right.

\section{Mean of finalised SeRvE scale}

The mean of the complete finalised scale, scored as a percentage of number of questions answered, is $68.7 \%$ (s.d. = 13.98). All the subscales have mean raw data scores of around 3.00, which gives scope for sensitivity to change. There was no significant difference in the percentage total means of in-patients and out-patients (Welch's $t$-test 0.994, $P=0.323$ ). This could be because even our in-patient sample contained few people who were acutely unwell.

\section{Discussion}

\section{The SeRvE scale}

This scale has been shown to be a reliable and valid measure of holistic recovery from mental illness. It is an inclusive questionnaire for service users to assess their own recovery and the only one to address spiritual and religious issues. The fact that meaningful subscales could be identified added further validity. There are two points of particular interest. First, despite negative scoring for negative questions, the well-being and ill-being factors for existential, social and religious issues do not cluster together, making well-being and ill-being separate concepts for each issue. This means that not only is it crucial to deal with the ill-being but just as important to help people find positive well-being. These may be two quite different tasks. Second, existential well-being was the largest factor in our analysis. Since the questions in this subscale are mainly concerned with meaning and experience of life, this reflects spiritual well-being in its broadest sense. Religious well-being, the specific formal and communal aspect of spiritual well-being, was the second most important factor. The relevance of these two subscales points to the importance of helping people explore their own spirituality/religion in a positive way. More specialised help is also required for the minority of service users who experience religious ill-being. Fulfilling spiritual needs in these ways is the task of spiritual care. The results show the importance of this for all mental health service users.

\section{Use of the SeRvE scale in practice}

The SeRvE scale is suitable for mental health service users of all religions and none, and thus could be used in a wide variety of cultural contexts, certainly within the UK, in primary and secondary care.

It can be used as a research tool to evaluate new interventions from the service user viewpoint. Results of the different subscales could help define how an intervention is working and which service users are most likely to be helped by it.

It also has potential in clinical practice:

(a) to be used as a new structured approach to taking a complete, person-centred history;

(b) to monitor the effectiveness of a particular treatment from the service user viewpoint;

(c) comparing scores from the subscales for different service users could assist in identifying interventions specifically targeted to the individual service user.

\section{Limitations of study}

The SeRvE scale needs to be tested in its finalised format, in a larger sample of service users including those with acute mental illness. Sensitivity to change and test-retest reliability for the SeRvE need to be established. Comparisons of clinician assessments of recovery from mental illness, for example using the HoNOS, with results using the SeRvE scale would be of further interest. The SeRvE scale may be considered too long to be administered to service users routinely in clinical practice, thus the formation of a shortened form is planned in a further study. 


\section{Implications}

The SeRvE has wide potential for evaluating interventions in mental health, both in research and in clinical practice. It is a self-report, user-designed scale to monitor recovery from mental illness from the service user's viewpoint. The scale includes measures of spiritual well-being and ill-being, both existential and religious. Factor analysis highlights the importance of these issues for service users. It points to the potential value of increased spiritual care for our service users.

\section{Acknowledgements}

Our grateful thanks are extended to: Carol Wilson, Head of Spiritual Care, Birmingham and Solihull Mental Health NHS Foundation Trust, who supported and assisted in both the study and the preparation of this paper; John Broggio, Statistician in Public Health, University of Birmingham; and Paul McDonald, Research Manager for Birmingham and Solihull Mental Health NHS Foundation Trust, for help with statistics. Also the members of Suresearch, University of Birmingham, for advice with the design of the scale. This research received no grant from any funding agency in the public, commercial or not-for-profit sector.

\section{About the authors}

Joanna M. Barber is an honorary researcher at Birmingham and Solihull Mental Health NHS Foundation Trust and a long-term mental health service user. Madeleine Parkes is a spiritual care advisor (formerly researcher) at Birmingham and Solihull Mental Health NHS Foundation Trust. Helen Parsons is a research fellow in the Division of Health Sciences at Warwick Medical School, The University of Warwick. Christopher C. H. Cook is professorial research fellow at the Project for Spirituality, Theology and Health at Durham University, Durham.

\section{References}

1 Bonney S, Stickley T. Recovery and mental health: a review of the British literature. J Psychiatr Ment Health Nurs 2008; 15: 140-53.

2 Stotland NL, Mattson MG, Bergeson S. The recovery concept: clinician and consumer perspectives. J Psychiatr Pract 2008; 14 (suppl 2): 45-54.

3 Deluty BM, Deluty RH, Carver CS. Concordance between clinicians' and patients' rating of anxiety and depression as mediated by private selfconsciousness. J Pers Assess 1986; 50: 93-106.

4 Wing JK Curtis RH, Beevor AS. HoNOS: Health of the Nation Outcome Scales: Report on Research and Development. Royal College of Psychiatrists, 1996

5 Perkins R. What constitues success? The relative priority of service users' and clinicians' views of mental health services. Br J Psychiatry 2001; 179: 9-10.

6 Coleman R. Recovery: An Alien Concept. Handsell Publishing, 1999.

7 Martyn D. The Experiences and Views of Self-Management of People with a Schizophrenia Diagnosis. Rethink, 2002.

8 Deegan PE. Recovery as a journey of the heart. Psychiatr Rehabil J 1996; 19: 91-7.

9 Ng RMK, Pearson V, Lam M, Law CW, Chiu CPY, Chen EYH. What does recovery from schizophrenia actually mean? Perceptions of long-term patients. Int J Soc Psychiatry 2008; 54: 118-30.

10 Ralph RO. Recovery. Psychiatr Rehabil Skills 2000; 4: 480-517.

11 Jacobson N, Greenley D. What is recovery? A conceptual model and explication. Psychiatr Serv 2008; 52: 482-5.

12 Fischer EP, Shumway M, Owen RR. Priorities of consumers, providers and family members in the treatment of schizophrenia. Psychiatr Serv 2002; 53: 724-9.

13 Katschnig H. Quality of life in mental disorders: challenges for research and clinical practice. World Psychiatry 2006; 5: 139-45.

14 Resnick SG, Rosenheck MD, Lehman AF. An exploratory analysis of correlates of recovery. Psychiatr Serv 2002; 55: 540-7.

15 Anthony WA. Recovery from mental illness: the guiding vision of the mental health service system in the 1990s. Psychosoc Rehabil J 1993; 24: 159-68.
16 Andresen R, Caputi P, Oades L. Stages of Recovery Instrument: development of a measure of recovery from serious mental illness. Aust N Z J Psychiatry 2006; 4: 972-80.

17 Diener E, Emmons RA, Larsen RJ. The Satisfaction with Life Scale. J Pers Assess 1985; 49: 71-5.

18 Gilbody SM, House AO, Sheldon TA. Outcomes research in mental health. Systematic review. Br J Psychiatry 2002; 181: 8-16

19 Holloway F. Outcome measurement in mental health - welcome to the revolution. Br J Psychiatry 2002; 181: 1-2.

20 Jerrell JM, Cousins VC, Roberts KM. Psychometrics of the Recovery Process Inventory. J Behav Health Serv Res 2006; 33: 464-73.

21 Test MA, Greenberg JS, Long JD, Brekke JS, Burke SS. Construct validity of a measure of subjective satisfaction with life of adults with serious mental illness. Psychiatr Serv 2005; 56: 292-300.

22 Young S, Bullock W. Illness Management and Recovery, and the Role of the Mental Health Recovery Measure in Outcomes Research. Ohio Coordinating Centre for Excellence in Illness and Recovery, 2003.

23 Tennant R, Hiller L, Fishwick R, Platt S, Joseph S, Weich S, et al. The Warwick-Edinburgh Mental Well-Being Scale (WEMWBS): development and UK validation. Health Qual Life Outcomes 2007; 5: 63-78.

24 Mental Health Foundation. Taken Seriously: The Somerset Spirituality Project. Mental Health Foundation, 2002 (http://www.mentalhealth.org. uk/publications/taken-seriously/).

25 Miller WR, Thoresen CE. Spirituality, religion and health: an emerging research field. Am Psychol 2003; 58: 24-35.

26 Cook CCH. Addiction and spirituality. Addiction 2004; 99: 539-51.

27 Tsuang MT, Simpson JC, Koenen KC, Kremen WS, Lyons MJ. Spiritual well-being and health. J Nerv Ment Dis 2007; 195: 673-80.

28 Fisher JW. Assessing spirituality and well-being among children and youth. Int J Child Spiritua 2009; 14: 272-88.

29 Ellison CW. Spiritual well-being: conceptualisation and measurement. J Psychol Theol 1983; 11: 330-40.

30 Bufford RK, Paloutzian RF, Ellison CW. Norms for the Spiritual WellBeing Scale. J Psychol Theol 1991; 19: 56-70.

31 Andrew C. My experience of schizophrenia - and recovery. Voices Forum, 2005 (http://www.voicesforum.org.uk/myex.htm).

32 MacDonald A. Milestones on my recovery road. Scottish Recovery Network, 2005 (http://www.scottishrecovery.net).

33 Deegan PE. The lived experience of rehabilitation. Psychosoc Rehabil J 1998; 11: 11-9.

34 Fischer EP, Shumway M, Owen RR. Priorities of consumers, providers and family members in the treatment of schizophrenia. Psychiatr Serv 2002; 53: 724-9.

35 McCabe R, Saidi M, Priebe S. Patient-reported outcomes in schizophrenia. Br J Psychiatry 2007; 191: s21-8.

36 King $M B$, Koenig HG. Conceptualising spirituality for medical research and health service. BMC Health Serv Res 2009; 9: 116-24.

37 O'Connell KA, Skevington SM. The relevance of spirituality, religion and personal beliefs to health related quality of life: themes from focus groups in Britain. Br J Health Psychol 2005; 10: 379-98.

38 Fallot RD. Spirituality and religion in psychiatric rehabilitation and recovery from mental illness. Int Rev Psychiatry 2001; 13: 110-6.

39 Hall DE, Meador KG, Koenig HG. Measuring religiousness in health research: review and critique. J Relig Health 2008; 47: 134-63.

40 Martsolf DS, Mickley JR. The concept of spirituality in nursing theories: differing world-views and extent of focus. J Adv Nurs 1998; 27: 294-303.

41 Mytko JJ, Knight SJ. Body, mind and spirit: towards the integration of religiosity and spirituality in cancer quality of life research. Psychooncology 1999; 8: 439-50.

42 Mountain DA, Muir WJ. Spiritual well-being in psychiatric patients. Ir J Psychiatr Med 2000; 17: 123-7.

43 Fisher JW, Francis LJ, Johnson P. Assessing mental health via four domains of spiritual well-being: the SH4DI. Pastoral Psychol 2000; 49: $133-45$.

44 Frey BB, Daaleman TP, Peyton V. Measuring a dimension of spirituality for health research: validity of the Spiritual Index of Well-Being. Res Aging 2002; 27: 556-77. 
45 Hill PC, Pargament KI. Advances in the conceptualisation and measurement of religion and spirituality. Implications for physical and mental health research. Am Psychol 2003; 58: 64-74.

46 Miller ED. Miller Measure of Spirituality, MMS. The development and validation of a new measure of spirituality. N Am J Psychol 2004; 6: 423-30.
47 Barber J, Parkes M. Handbook of Spiritual Care. Birmingham and Solihull Mental Health Trust, 2009.

48 Gomez R, Fisher JW. Domains of spiritual well-being and development and validation of the Spiritual Well-Being Questionnaire. Pers Individ Dif 2003; 35: 1975-91.

\section{Appendix}

\section{Service-user Recovery Evaluation (SeRvE) scale}

Please answer each question by circling the number, depending on how you have felt this last week

How you have felt about yourself and your life during the last week

Disagree strongly (1), disagree somewhat (2), don't know (3), agree somewhat (4), agree strongly (5)

\begin{tabular}{|c|c|c|c|c|c|}
\hline I feel thankful for my life & 1 & 2 & 3 & 4 & 5 \\
\hline I feel a sense of meaning and purpose in my life & 1 & 2 & 3 & 4 & 5 \\
\hline I am confident I can cope with most things in life & 1 & 2 & 3 & 4 & 5 \\
\hline I feel ashamed of having a mental health problem & 1 & 2 & 3 & 4 & 5 \\
\hline I can find or create something beautiful in life & 1 & 2 & 3 & 4 & 5 \\
\hline I feel my life is pointless & 1 & 2 & 3 & 4 & 5 \\
\hline I have hope for the future & 1 & 2 & 3 & 4 & 5 \\
\hline I can love myself & 1 & 2 & 3 & 4 & 5 \\
\hline I have lost my identity/sense of who I am & 1 & 2 & 3 & 4 & 5 \\
\hline I believe I have the ability to overcome my problems & 1 & 2 & 3 & 4 & 5 \\
\hline I am upset by the stigma of having a mental health problem & 1 & 2 & 3 & 4 & 5 \\
\hline I can do satisfying things despite my problems & 1 & 2 & 3 & 4 & 5 \\
\hline I am positively inspired by the beauty of nature & 1 & 2 & 3 & 4 & 5 \\
\hline I have lost inner motivation & 1 & 2 & 3 & 4 & 5 \\
\hline I am positively inspired by music/the arts or literature & 1 & 2 & 3 & 4 & 5 \\
\hline
\end{tabular}

How you have felt emotionally during the last week

None of the time (1), sometimes (2), don't know (3), quite a bit (4), most of the time (5)

\begin{tabular}{|c|c|c|c|c|c|}
\hline Happy & 1 & 2 & 3 & 4 & 5 \\
\hline Agitated or fearful & 1 & 2 & 3 & 4 & 5 \\
\hline At peace & 1 & 2 & 3 & 4 & 5 \\
\hline Guilty & 1 & 2 & 3 & 4 & 5 \\
\hline Joyful & 1 & 2 & 3 & 4 & 5 \\
\hline Content & 1 & 2 & 3 & 4 & 5 \\
\hline Angry & 1 & 2 & 3 & 4 & 5 \\
\hline
\end{tabular}

How you have related to other people during the last week?

Disagree strongly (1), disagree somewhat (2), don't know (3), agree somewhat (4), agree strongly (5)

\begin{tabular}{|c|c|c|c|c|c|}
\hline I feel other people are against me & 1 & 2 & 3 & 4 & 5 \\
\hline I have some meaningful and close relationships & 1 & 2 & 3 & 4 & 5 \\
\hline I feel loved by some others & 1 & 2 & 3 & 4 & 5 \\
\hline I feel cut off from the rest of the world & 1 & 2 & 3 & 4 & 5 \\
\hline I feel suspicious of most people and find it hard to trust & 1 & 2 & 3 & 4 & 5 \\
\hline My problems make me isolated from other people & 1 & 2 & 3 & 4 & 5 \\
\hline I love some other people & 1 & 2 & 3 & 4 & 5 \\
\hline I feel I need to isolate myself from other people & 1 & 2 & 3 & 4 & 5 \\
\hline I have destructive thoughts towards some other people & 1 & 2 & 3 & 4 & 5 \\
\hline
\end{tabular}




\section{Service-user Recovery Evaluation (SeRvE) scale continued}

Your personal religious beliefs and practices during the last week

If you believe in a God, higher power, divine spirit, force for good or anything similar, even if only a little, please write your preferred word in here:

Please substitute your word for $X$ in the following questions, or circle ' $n / a^{\prime}$ (not applicable) if you think the question is not relevant to you

Disagree strongly (1), disagree somewhat (2), don't know (3), agree somewhat (4), agree strongly (5)

\begin{tabular}{|c|c|c|c|c|c|c|}
\hline I feel I am loved by $X$ & 1 & 2 & 3 & 4 & 5 & $\mathrm{n} / \mathrm{a}$ \\
\hline I feel that there is a part of $X$ within me & 1 & 2 & 3 & 4 & 5 & $\mathrm{n} / \mathrm{a}$ \\
\hline My faith/spiritual belief is helpful to me & 1 & 2 & 3 & 4 & 5 & $\mathrm{n} / \mathrm{a}$ \\
\hline I feel anger towards me from $X$ & 1 & 2 & 3 & 4 & 5 & $\mathrm{n} / \mathrm{a}$ \\
\hline I find it helpful to pray to $X$ & 1 & 2 & 3 & 4 & 5 & $\mathrm{n} / \mathrm{a}$ \\
\hline I feel spiritual power/forces are controlling me or others & 1 & 2 & 3 & 4 & 5 & $\mathrm{n} / \mathrm{a}$ \\
\hline I find it helpful to attend religious services/rituals & 1 & 2 & 3 & 4 & 5 & $\mathrm{n} / \mathrm{a}$ \\
\hline I feel that $X$ has a purpose for my life & 1 & 2 & 3 & 4 & 5 & $\mathrm{n} / \mathrm{a}$ \\
\hline My faith/spiritual belief gives me difficult thoughts & 1 & 2 & 3 & 4 & 5 & $\mathrm{n} / \mathrm{a}$ \\
\hline
\end{tabular}

\section{'We've got another one for you!' Liaison psychiatry's experience of stigma towards patients with mental illness and mental health professionals}

Jim Bolton ${ }^{1}$

The Psychiatrist (2012), 36, 450-454, doi: 10.1192/pb.bp.112.038646

${ }^{1}$ St Helier Hospital, Carshalton, UK

Correspondence to Jim Bolton (jim.bolton@swlstg-tr.nhs.uk)

First received 18 Jan 2012, final revision 19 Jun 2012, accepted 12 Jul 2012
Aims and method To assess stigmatising attitudes towards mental illness and psychiatric professionals experienced by UK liaison psychiatry staff. A questionnaire asked about the impact of these events on patient care and for suggestions for tackling stigma in the general hospital.

Results Out of 72 multidisciplinary respondents, over three-quarters had experienced stigmatising attitudes towards mental illness by general hospital colleagues at least monthly. Two-thirds reported instances where stigmatisation had an adverse impact on patient care, and over a quarter reported stigmatising attitudes towards mental health professionals. Suggestions for combating stigma included educational initiatives, clear clinical communication, and the provision of high-quality liaison services.

Clinical implications Liaison psychiatry is well placed to both recognise and combat stigma in the general hospital. This can help to ensure that patient care is comprehensive, safe and respectful.

Declaration of interest None.
Stigma, originally a physical mark inflicted by branding, is any characteristic or attribute - including an illness - that marks an individual out as different and evokes a sanction. Stigmatisation more often arises from mental rather than physical illnesses and may result in prejudice and discrimination. 'Stigma by association' can also affect related occupations such as psychiatry. It has been suggested that the biggest single obstacle to the development of mental healthcare and improvement in the quality of life of those with mental illness is stigmatisation. ${ }^{2}$ 